\title{
Nurturing a Teaching and Learning Community in Business \\ Education: Disseminating Practical Strategies From a Technological University.
}

Roisin Donnelly

Technological University Dublin, roisin.donnelly@tudublin.ie

Follow this and additional works at: https://arrow.tudublin.ie/ltcart

Part of the Adult and Continuing Education Commons

\section{Recommended Citation}

Donnelly, R. (2021). Nurturing a Teaching and Learning Community in Business Education: Disseminating Practical Strategies from a Technological University. Journal of Education for Business.

This Article is brought to you for free and open access by the Learning Teaching \& Assessment at ARROW@TU Dublin. It has been accepted for inclusion in Articles by an authorized administrator of ARROW@TU Dublin. For more information, please contact arrow.admin@tudublin.ie, aisling.coyne@tudublin.ie, gerard.connolly@tudublin.ie.

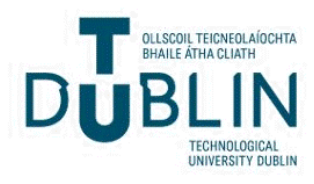




\title{
Nurturing a Teaching and Learning Community in Business Education: Disseminating \\ Practical Strategies from a XXX
}

\author{
Roisin Donnelly \\ Head of Learning Development in Business \\ Technological University Dublin \\ Ireland \\ Roisin.Donnelly@TUDublin.ie \\ https://orcid.org/0000-0001-9053-6375
}

\begin{abstract}
This paper discusses a professional perspective for nurturing teaching and learning (T\&L) practice to support a community of Business Educators in a XXX in Ireland. It is aimed at deans and associate deans by disseminating practical T\&L strategies for use as a basis of envisioning their own School approaches, and in so doing is offering an approach to the systemizing of administration of academic organizations. It explores faculty professional development, communication strategies and faculty engagement initiatives - all designed to support the ongoing development of a community of Business educators. Addressing the challenges of T\&L at scale requires strategic pedagogical change, working with faculty, professional support teams, students and the wider University to ensure the successful delivery of innovative Business programmes for today’s learner diversity.
\end{abstract}

Keywords: Business Education; Community of educators; Communication Strategies; Innovation Exchange; Signature Pedagogy; Teaching and Learning. 


\section{Introduction}

Business education today continues to see students honing their skills through practical experience, with university Business education programmes providing rich opportunities for relevant, real world learning opportunities. In order to respond effectively to new market opportunities, faculty need to continue to develop their capacity and capability to deliver a flexible and responsive portfolio of provision to meet the specific needs and demands of employers and the workforce. Eyre et al. (2008) have argued that one of the key challenges is to ensure that faculty in higher education have the necessary skillset to support this activity, which require a breadth of appropriate skills and knowledge, along with the robustness, yet flexibility, of the institution's support systems. This challenge remains true today and to meet it, there is a need for innovative faculty strategic initiatives that will transform the student experience in undergraduate and postgraduate programmes in Business Schools. This work is aimed at Deans and Associate Deans as their responsibilities and oversight may vary due to the synergies between these areas but they commonly include undergraduate education, graduate education, research, administration and finance, and faculty affairs. The paper discusses an approach that aims for joined-up thinking and exchange of innovation within teaching and learning, coupled with strategies for communication and dissemination across Business Schools in a XXX.

\section{Context of Business Education in the XXX}

Ireland's XXX was formed from the merger of three existing higher education institutions. Technological universities offer programmes that are vocationally and professionally oriented, and the introduction of the XXX has reshaped higher education in Ireland. In terms of current structure, there are four Colleges in the university. The XXX, which forms the context for this paper, is one 
of Ireland's largest Business schools in terms of full-time and part-time student enrolment and has been in existence for over thirty years. There are five Schools in the College - Marketing, Accounting and Finance, Management, Retail and Services Management and the Graduate Business School. The College offers both undergraduate degree and postgraduate programmes to approximately 5,000 students across a range of Business disciplines. Its programmes at certificate, diploma, graduate, and post-experience levels seek both to pursue academic excellence and to nurture applied expertise. These programmes provide industry in Ireland with a valuable resource, which is responsive to the needs of both individual firms and broad sectors from disparate companies and industries. There is a dual aim of delivering flexible, authentic and impactful executive education to busy employees and of making a positive impact on the local community. New developments in the provision of professional education by the College reflect recent changes in the workplace and involve working with emerging needs in the economy. The College has over 170 full-time faculty, many with extensive business experience.

As can be imagined for this Business College with such a history, moving into a XXX context has meant that there is significant change happening to the existing institutional structure and fabric, and such system-wide restructuring can have profound impact for students and faculty. The XXX was an amalgamation of three existing higher education institutions and the drive for its creation came from Ireland's National Strategy for Higher Education to 2030. The vision set out for technological universities distinguishes them from traditional universities in that teaching is focused on career-relevant courses. Against this backdrop of institutional change, the College of Business is continuing to hone its professionally oriented programme provision for students. The Business degrees typically encompass a wide group of programmes, some highly specialized and 
others more interdisciplinary. The combination of academic challenge and practical focus makes studying for a Business degree highly appealing for those attracted to the collaborative learning environment offered by the Business College. In a competitive business education marketplace in Ireland, with a number of institutions offering similar programmes, one of the aspects that help the College of Business stand out is the excellent quality of its teaching and learning environment.

This paper acknowledges that media debate on the value of Business schools worldwide is growing. A recent article in the Times Higher Education (THE) (2019) argues that Business and Management schools are highly successful in financial terms, and provide valuable income to their wider universities, but opinion remains sharply divided on how successful they have been intellectually. This has previously been highlighted in the U.S., where the reputation of some Business programmes has also suffered - Business schools provide students with many technical skills, but they appear to do little, or nothing, to foster responsibility and accountability (Podolny, 2009). To counter this, Parker (2018) has posited that an entirely new way of thinking about management, business and markets is needed. Specifically for the context of this paper, Hubbard (2019) asks the question - how should Business Schools teach their primary subject? Lessons learnt are shared for Deans and Associate Deans in T\&L.

\section{Nurturing a Community of Business Educators}

Mabrouk (2018) argues that among the many challenges of being an academic dean, the biggest is managing difficult conversations. However alongside this, there are plentiful opportunities to meet and collaborate with a wide array of energetic, talented and dedicated faculty members, administrators, students, alumni and others. How best to bring all these conversations together? 
Each of the five Schools in the College share characteristics which can enhance them as Learning Communities: faculty are committed to lifelong learning; learning is seen as the central activity of both individuals and the Schools as a whole; collaboration is the major thread in each School's culture; and continuous improvement is built into the very fabric of each School. As such, it is important to nurture this community of Business educators by creating continuous learning opportunities, promoting inquiry and dialogue, encouraging collaboration and team learning, establishing systems to capture and share learning, empower faculty toward a collective vision and connect the College to its environment. The philosophy underpinning such an approach is one which equates with the notions of Schön (1983) where learning is the interaction of thinking and action and teachers are propelled into broadening their own knowledge base as well as their strategies for teaching and inspiring learning. In this way, they have the potential for meeting the characteristic of the Learning Community where both individualism and collaboration are central elements of the overall School culture (Fullan 1993; Hargreaves, 1994), and which impinge upon all stakeholders. As Donahoe (1993, p.301) argues, "Change requires a dynamic, open, selfexamining, interactive system.”

Creating a PD learning community can make use of the fact that many faculty in Business Education are already active on social media, posting offers to share resources and communicate lessons learned from their T\&L practice. This type of sharing provides a crucial source of faculty support and knowledge sharing from which peers can benefit, and can also open up a forum to express concerns and frustrations in a safe environment. Establishing this digital community for faculty to exchange innovations and ideas, ask questions, share resources and seek guidance has been received very positively across the College, with the academic dean for faculty development 
spearheading the work. To nurture faculty teaching and learning approaches in the community, a number of initiatives have been introduced, and discussed in the next section of the paper.

\section{Consolidating and Communicating the Signature Pedagogy in the College}

The notion of signature pedagogies was developed by Shulman (2005, p.525) when looking at education in the professions - "These are characteristic forms of teaching and learning that organise the fundamental ways in which future practitioners are educated for their new professions." They encapsulate critical aspects of the three fundamental dimensions of professional work (to think, to perform and to act with integrity). Each profession has its own characteristic way of doing this, reflecting the differing emphasis it places on each of the three dimensions to identify the characteristic ways in which each subject trains its students to think, perform and act like members of that community of practice who share that particular ontology, epistemology, methodology, praxis and discourse.

As Shulman explains, a signature pedagogy has three dimensions: surface structure, deep structure, and an implicit structure. Surface structures consist of concrete, operational acts of teaching and learning, while deep structures reflect a set of assumptions about how best to impart a certain body of knowledge and know-how. The implicit structure includes a moral dimension that comprises a set of beliefs about professional attitudes, values, and dispositions (pp.54-55). At its most basic, it is the habits of head, hand, and heart are inherent to the Business Education profession and how these can be fostered in our students. The signature pedagogy allows practice to become the focus of transformational learning in the College. The focus of this pedagogy is on 'animation' (bringing 'life' into situations, 'reflection' (creating space to reflect) and 'action' (the practical application 
of learning which is as important as text based evidence). Teaching a subject specialism becomes just one aspect of pedagogy, and the practice of that specialism, the practical tests, experiments and action research, the 'learning by doing', become key.

The pedagogy forges a connection between programme coursework, practice, and policy-making in the field of Business Education. This is a distinctive set of practices and theories that guide Business Education in the College and underpinning it is consideration of the values that our signature pedagogy should embrace. Firstly offer outstanding T\&L and ensure it is maintained, supported, celebrated and developed on an ongoing basis. Learning through doing is a strong feature through utilizing complex case studies, live industry projects, problem-based learning, reflective practice, critical thinking and technology-enhanced business education. Secondly, encouraging ongoing critical-reflective, collaborative inquiry by faculty. Thirdly, providing support for programme leaders (Chairs) with a focus on inclusion of graduate attributes to the curriculum design process, suitable approaches to continuous assessment across all programmes, and college-wide strategies for student feedback.

Case Study teaching is one of the key teaching and learning pedagogies in the majority of Programmes in the College of Business which embodies all these practices. Recent supports introduced to share Faculty practices across all Schools included a Case Study Colloquium and a subsequent eBook resource which garnered enthusiasm from all levels of faculty. Ten members from across the five Schools on the College presented their particular approach to case study teaching and assessment and a guest speaker from the University of London business school provided an overview of international practice. The 'eBook Ideas Collection on Case Study 
Teaching and live project industry engagement' was an effective way of collating and disseminating both how Faculty in the College design learning and teach using this pedagogy. From the Colloquium, there arose a need for a Case Writing Workshop for faculty who are interested in writing their own cases for use in their programmes. Attending classes in case study teaching provides a clear sense of what is involved for both students and faculty - the Signature Pedagogy observation in action. Of particular interest currently is student development for case study competitions in Marketing, the Live Case Study presentations with local companies/industry, and student poster presentations on their case studies in Accounting \& Finance. Faculty have also been encouraged to disseminate pedagogical research and scholarly activity in case study teaching. It is important to know what we are doing as part of the signature pedagogy works. This will involve interrogating, researching and growing an evidence-base our T\&L practice. There are clear niche areas of good practice in different Schools, but as not all faculty may be aware of them, this is one way to help. Hubbard (2019) argues that Business schools need to bundle together the disparate activities of research, teaching, and experiential learning as such bundling unlocks the hidden value of Business Education. Figure 1 shows an approach that can be used to capture the scholarship underpinning T\&L in business education, involving faculty, peers and students across the College. 


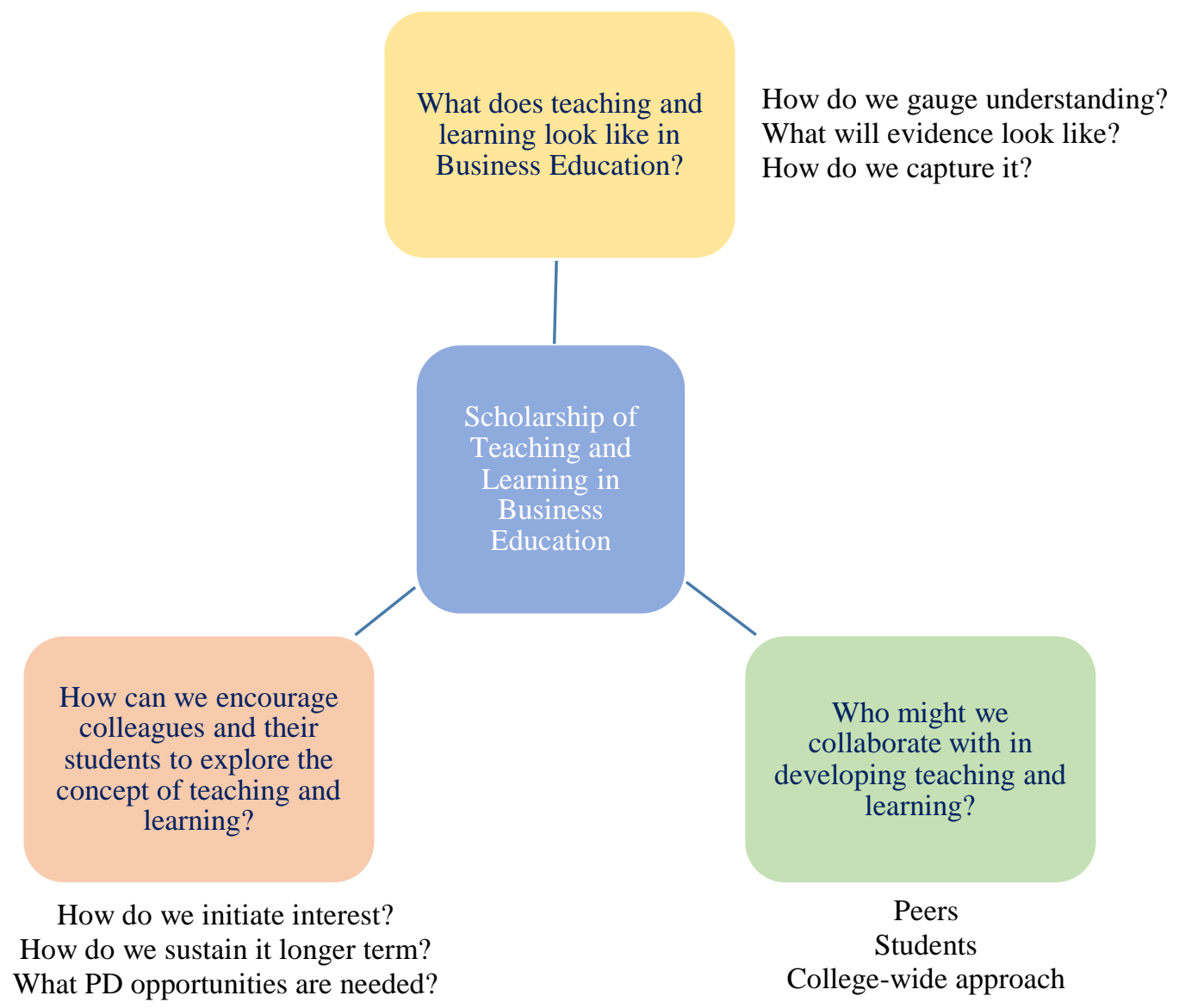

Figure 1: Exploring Opportunities for the Scholarship of T\&L in Business Education

\section{Supporting Programme Teams across Business Education}

New Associate Deans can benefit significantly from getting to know all the Programme Chairs in the College and recognizing that each has its own culture. Mabrouk (2018) advocates taking time and focusing effort on learning the cultures of various Schools and Departments which can pay dividends in the longer term. Supporting the Programme Chair/Leader role is integral to nurturing the community of Business educators in the College. Programme Leaders have key responsibilities for the development and management of academic programmes, and work with their Teams to 
ensure their programmes are viable, current and relevant to the needs of stakeholders. Importantly, Programme Leaders are positioned to lead and support their Teams on issues of quality and academic standards, and to ensure the support of students. Leadership here involves guiding, supporting and working with the Programme Team to ensure the 'overall health and well-being of the programme'. This means that the programme should have vitality and viability - that it is recruiting well, students are performing satisfactorily, student- Faculty relationships are positive and productive, learning and teaching experiences are dynamic, and administration runs smoothly.

The responsibilities of the Programme Chair include academic leadership in two dimensions - by creating a unified and coherent academic programme made up of a collection of modules, and by the leadership of academics - supporting peers in meeting their specific responsibilities across the programme. Integral to both is the importance of creating productive and positive inter-personal relationships across a wide array of colleagues: quality and administrative officers, academic developers, academic peers, senior academic leaders and of course, students.

A study by O’Neill et al. (2014) for the Irish HE context highlighted supports for Programme Teams. There is a need in our curriculum design work to create and assist programme teams in creating and sustaining an on-going curriculum philosophy. This can be created in workshops and supplemented by some creative visual approaches, as described by Healey et al. (2011). There is also a need for further education to improve Faculty knowledge and critique of their own and other curriculum frameworks. 
In the College, a new Programme Chairs Forum with an accompanying online repository for resources supports Chairs in their work. Comprehensive ranges of resources are now available on key topics identified for the College by the Dean and the Heads of School, with templates uploaded for use in programmes on Student Engagement Activities, Assessment \& Feedback Strategies, AACSB common modules planning, Student \& Industry testimonials, and a new online calendar to support programme committee work across the academic year.

Aligning the Chairs Forum with annual Quality Assurance (QA) processes and a series of support workshops for new Programme Chairs will in this time of change in the $X X X$, provide faculty with clear communication on new QA processes. Accreditation is undoubtedly important to Business Schools by informing on the quality of a Business School education, and of a School's ability to drive innovation. An article by Hughes (2018) discusses the value [of accreditation] being not the label itself, but in the improvement cycle that is associated with it.

Faculty in the College share a commitment to quality curriculum design and through a process of ‘closing the loop’ reflection, they are considering the next stages for common module development in undergraduate business programmes. An essential part of this work involves faculty disseminating formative and summative assessment and feedback strategies and rubrics, which is discussed in this next section. Findings from Pringle \& Micel (2010) have been interesting for raising awareness for assessment methods that Business Schools use, including their continuing use of indirect measures, the amount of time that assessment takes, the extent of faculty resistance, and the results that assessment yields. 


\section{Disseminating Teaching and Learning Practice across the College}

For those who are charged with planning and facilitating pedagogical change in higher education, there is acknowledgment that dissemination of learning and teaching innovation requires approaches to change that are socially-contextualised, dynamic and self-reflexive. Embedding innovation in a range of domains benefits from disseminating innovations beyond disciplinary silos across faculties. Kahn \& Anderson’s (2019) recent research on moving towards excellence in teaching in HE includes the need to learn from student feedback and peer review; recognizing students as consumers; building effective partnerships with students and colleagues; and choosing effective teaching practices.

A new virtual learning environment (Brightspace) was implemented in the university recently. It was identified by Heads of School that it is important to share T\&L innovations from Faculty across the College of Business. With input from various faculty in the College, a T\&L Resource Portal on Brightspace has been designed as a dynamic place for Faculty to exchange their ongoing innovations in T\&L, make short videos explaining their approach and lessons learnt as they engage in innovative practices. Through the new Resource Portal, Faculty can also provide exemplars from their technology engagement. This aligns with what Treleaven et al. (2012) advocate for Business Schools - having accessible resources, tools and databases that support implementation of innovation, and utilizing the capacity of communities of practice and distributed leaders to generate organisational commitment and seed activities. Although it is early days for the Portal, Faculty have shown enthusiasm and commitment for exploring and implementing their innovative practice, and it is a way to create a space where academics are free to experiment and evaluate innovations. In line with advice from Mintz (2019), these "islands of innovation,” which are 
environments free from normal institutional constraints, can serve as test beds and assessment sites for innovations that might later be scaled, and as a way to build an innovation community by facilitating campus conversations about innovation, pedagogy, curricular design, online learning, and assessment.

Further aspects of the dissemination strategy involve monthly 'Lunch \& Learn' sessions for Faculty and a 'Business of Learning' Newsletter. The latter is designed as a way to look back at what has taken place on T\&L initiatives over a past semester, as well as highlighting some early ideas for what is coming up in the new academic year. The former have an applied focus, are used for ideas generation, and ultimately are about a space for colleagues to share practice on current themes in T\&L identified by them as significant (e.g. consistent feedback rubric design and use across UG degree programmes). The challenge and the opportunity is to have different faculty attend to share their T\&L practice each time. Interesting discussions that emerged were how to avoid over-assessment for students, how to plan for this as a programme team, as well as how can rubrics be used to show advancement in Business practice.

Dissemination strategies also extend to a new' Spotlight on...Series' which is being introduced with a workshop on Critical Thinking aimed at all Faculty in Business Education considering/planning to integrate critical thinking skills into Undergraduate programmes. A new A-Z Digital Resource Series in collaboration with the College Librarians, has produced a short pedagogical guide each semester on making best use of digital disciplinary resources in academics' practice with their students. Podcasts are planned for further involving Faculty by giving short 
interviews on how they are using the resources and conversational tips for their colleagues for increasing use with students.

Blended learning for Business Education is an important strategy which is continuing to be developed and implemented for the College. Part of the strategy involves progressing an agreed set of principles and practices for Faculty College-wide. This is in recognition that today's Business Education marketplace and the nature of delivery is very diverse. Traditional degrees still dominate but students might now be studying while working through an apprenticeship programme, they might be learning via an online qualification with delivery over their mobile phone, or they might be taking a micromasters or digital badge. The Chartered Association of UK Business Schools (CABS) report from a national 2019 survey that there is recognition of the growth potential in the provision of online courses, with 59\% of respondents citing digital/online provision as a big opportunity for growth over the next ten years and half seeing it as a growth opportunity at present. Almost nine out of ten (89\%) Business Schools in the UK either already offer or are planning to offer blended degrees with part online and part on campus study. Further indications of innovation are also evident - half the respondents already offer an online degree that is not an MBA and 38\% have an online MBA. However, only 20\% deliver a MOOC, 19\% offer a microcredential, and $10 \%$ provide digital badges. Figure 2 is a synopsis of the areas in Faculty learning development that are key to the ongoing support of teaching and learning in the College of Business: the Signature Pedagogy, disseminating and embedding the T\&L culture, supporting programme teams/Chairs, blended learning and maximizing the benefits from the Quality Enhancement process. 


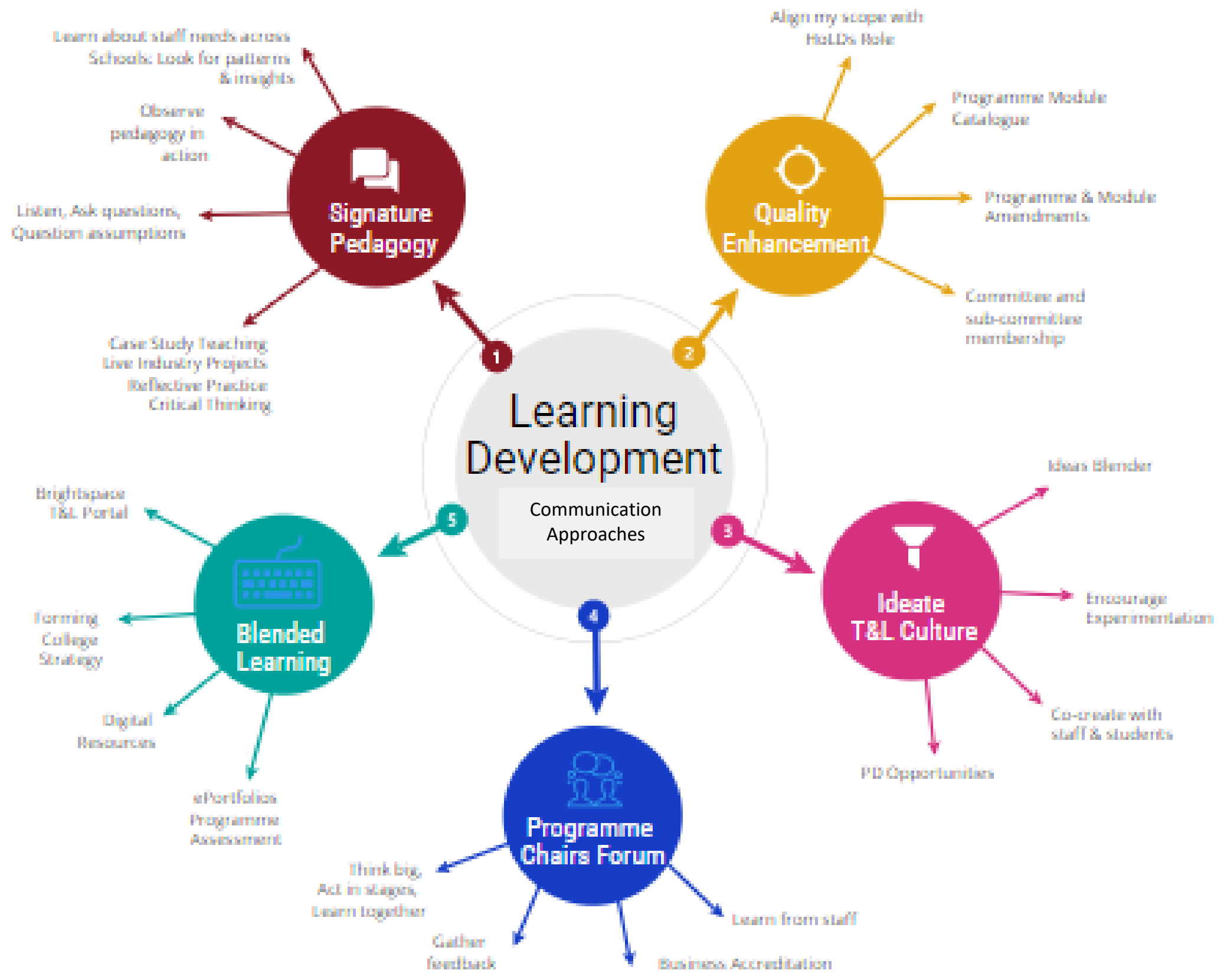

Figure 2: Learning Development supporting Teaching and Learning in Business Education 


\section{Conclusion}

As we facing into our uncertain future, and just having experienced a number of months of unprecedented times in higher education, Deans and Associate Deans have experienced the need for speedy action in their role. Baker (2020) describes it a coalescing of functional areas across our respective campuses happening at a rapid pace. We have witnessed institutions disseminating online resources and teaching toolkits to faculty in an open and responsive way. During this time, undoubtedly Deans and Associate Deans of Teaching and Learning have been grappling with complex problems of broad scope and significant impact across their Business Schools but using strategies that leverage the active, collegial participation of their large teams can be invigorating for their role. As Ireland's XXX settles into its new structures and academic rhythm, the Deans and Assistant Deans continue to grow the community of Business educators with shared values, underpinning theory and body of evidence, and we are seeing sharing beyond traditional disciplinary silos and commonalities emerging. As we exchange and examine our practice in such a community, we are seeking to address the challenges associated with achieving sustained improvement and systemic change in a XXX context.

\section{References}

Baker, V.L. (2020). How Colleges Can Better Help Faculty During the Pandemic. Inside Higher Ed.

CABS (2019). The Changing Shape of Business Education Provision.

Donahoe, T. (1993). Finding the Way: Structure, time, and culture in school improvement. Phi Delta Kappan, December, 298-305.

Eyres, R.D., Hooker, E., \& Pringle, A.J. (2008). The Higher Education Academy - Workforce development. UK: HEA. 
Fullan, M. (1993). Change Forces. London: Falmer Press.

Hargreaves, A. (1994). Changing Teachers, Changing Times. Toronto: OISE Press.

Healey, M, Bradford, M, Roberts, C., \& Knight, Y (2011). Collaborative discipline-based curriculum change. International Journal of Academic Development, 1-14.

Hubbard, G. (2019). The Real Value of Business Schools. BIZeD.

Hughes, A. (2018). MBA Accreditation: What Does It All Mean? BusinessBecasuse.

Kahn, P., \& Anderson, L. (2019). Developing Your Teaching: Towards Excellence (2 ${ }^{\text {nd }}$ Edition). London: Routledge.

Mabrouk, P.A. (2018). The Indispensable Associate Dean. Inside Higher Ed.

Mintz, S. (2019). Faculty as Drivers of Innovation: The real key to academic innovation. Inside

O’Neill, G., Donnelly, R., \& Fitzmaurice, M. (2014). Supporting Programme Teams to Develop Sequencing in Curricula in Higher Education. International Journal of Academic Development, 19(4), 268-280.

Parker, M. (2018). Why we should bulldoze the business school. The Guardian.

Podolny, J. (2009). Are Business Schools to Blame? Harvard Business Review.

Pringle, C., \& Michel, M. (2010). Assessment Practices in AACSB-Accredited Business Schools. Journal of Education for Business, 82(4), 202211.

Schön, D. (1983). The Reflective Practitioner. New York: Basic Books.

Shulman, L.S. (2005). Signature Pedagogies in the Professions. Daedalus, 134(3), 52-59.

THE (2019). Do business schools still have brand value?

Treleaven, L., Sykes, C. \& Ormiston, J. (2012). A dissemination methodology for learning and teaching developments through engaging and embedding. Studies in Higher Education, 37(8), 747-767. 